\title{
Enhanced Biodegradation of Anthracene by Multi- Substrate Progressive Domestication of a Mixed Microbial Consortium With Pseudomonas_Aeruginosa DM3
}

\section{Wei Li}

China University of Mining and Technology School of Environment Science and Spatial Informatics

Yanzehua Liu

China University of Mining and Technology School of Environment Science and Spatial Informatics

Dan Li

China University of Mining and Technology School of Environment Science and Spatial Informatics Liping Wang ( $\nabla$ wlpcumt@126.com )

China University of Mining and Technology School of Environment Science and Spatial Informatics https://orcid.org/0000-0001-7263-1037

\section{Zhen Mao}

China University of Mining and Technology School of Environment Science and Spatial Informatics

\section{Qi Wang}

China National Heavy Duty Truck Group Co.,Ltd

\section{Research Article}

Keywords: Multi-substrate domestication, Pseudomonas_aeruginosa DM3, Biodegradation, Anthracene, Coking wastewater sludge, Mixed microbial consortium

Posted Date: March 17th, 2021

DOl: https://doi.org/10.21203/rs.3.rs-292903/v1

License: (a) This work is licensed under a Creative Commons Attribution 4.0 International License. Read Full License 


\section{Abstract}

The degradation of polycyclic aromatic hydrocarbons has attracted much attention. Based on toluenecatechol-anthracene multi-substrate progressive domestication, a mixed microbial consortium with synergistic metabolic activity was screened from the activated sludge of coking wastewater. Highthroughput sequencing showed that the consortium was dominated by Flavobacteriia at the class level, with the proportion increasing from $8.88 \%$ to $56.41 \%$ after domestication, and that Myroides and Brevundimonas dominated at the genus level, increasing from less than $1 \%$ to $55.53 \%$ and $12.28 \%$, respectively. Under temperature conditions of $30^{\circ} \mathrm{C}$, a pH of 7 , and an initial anthracene concentration of $40 \mathrm{mg} \mathrm{L}^{-1}$, the degradation ratio reached $85.7 \%$ just 16 days after inoculation. Degradation ratio of Anthracene $\left(40 \mathrm{mg} \mathrm{L}^{-1}\right)$ via the consortium plus an indigenous strain Pseudomonas_aeruginosa DM3 on the sixth day (83\%) equated to that in the control group without DM3 on the 12th day. The first-order rate constant $\left(k=0.240\right.$ and $\left.0.159 \mathrm{~d}^{-1}\right)$ was calculated for the anthracene degradation within 10 days, with a corresponding half-life by the consortium of 2.9 days with DM3 and 4.4 days without DM3. The metabolites 1-naphthol, dibutyl phthalate, and 1,2-benzene dicarboxylic acid, mono (2-ethylhexyl) ester were presented in the reaction, inferring the metabolic pathway of phthalic acid. Our work revealed that inoculating the mixed microbial consortium with indigenous Pseudomonas aeruginosa DM3 has the potential for removing polycyclic aromatic hydrocarbons.

\section{Introduction}

Polycyclic aromatic hydrocarbons (PAHs) are a large class of environmentally-persistent organic compounds with high toxicity. They have serious and widespread impacts on human and ecosystem health and thus are of significant concern (Gaur et al. 2018). Anthracene (ANT), a three-ring PAH, is derived from coal tar and mainly used in the chemical industry for products such as dyes, plastics, and pesticides (Prasanna et al. 2008). It is frequently regarded as a model compound for PAH biodegradation research because of its low solubility and structural similarity with other low molecular weight PAHs such as phenanthrene (Behera et al. 2018; Hadibarata et al. 2013). Bioremediation technologies are efficient and sustainable for treating PAHs from contaminated sites at a low cost. However, stable molecular structure and insolubility of PAHs, as well as low bioavailability of the specific microorganisms that degrade them result in low metabolism of pollutants, limiting bioremediation (Elliot et al. 2011; Patowary et al. 2018).

Whether bioremediation in water or soil, enhancing solubility of PAHs or promoting desorption of contaminated soil is the premise and basis of bioavailability. In this respect, many studies have reported the role of synthetic surfactants and biosurfactants for increasing the solubility of hydrocarbons and improving the degradation of hydrophobic compounds by microorganisms (Lee et al. 2018; Tian et al. 2016). Compared to synthetic surfactants, biosurfactants have similar chemical functions but are less toxic and more biodegradable. At present, the focus of biosurfactant production is to reduce production costs, optimize fermentation conditions, and improve purification processes. Cazals et al (2020) boosted production using batch bioreactors and readily available nutrients. However, research on the structure and 
properties of biosurfactants is incomplete (Xu et al. 2020), and the application of biosurfactants requires monitoring for increased environmental risks. An alternative strategy is to isolate biosurfactant-producing microorganisms from contaminated sites and co-culture them with PAH-degrading bacteria to improve the breakdown of PAHs, and sustainably produce biosurfactant molecules (Mnif et al. 2017). Most researches have focused on the co-cultivation of biosurfactant-producing bacteria with a single or artificial bacterial consortium (Dean et al. 2001; Wanapaisan et al. 2018). Due to incompatibility and antagonism, a lack of cooperation between bacteria is common, and the microbes may not adapt to external environments (Zafra et al. 2017). Few studies have integrated technology on the enhanced degradation of PAHs between indigenous biosurfactant-producing bacteria and PAHs-degrading bacterial consortia. Zhou et al (2020) found that the introduction of indigenous biosurfactant manufacturer Acinetobactersp. Y2 changed the bacterial community structure and upregulated the expression of degradation-related genes.

In fact, the biodegradation and bioremediation of PAHs also depend on the microbial population and how it can adapt to an environment (Mnif et al. 2017). In contrast to specific dominant bacteria, mixed population consortia with a broad range of enzymatic mechanisms perform well in terms of substrate tolerance and degradation rate (Sun et al. 2010). In general, a single target pollutant was used for the domestication and enrichment of microorganisms. Based on the co-metabolism theory, the screened bacterial consortium has a higher metabolic ability and greater environmental adaptability when multisubstrate domestication is used. Furthermore, the main metabolites in the degradation process as cosubstrates contribute to reducing the accumulation of intermediates and eliminating their inhibitory effects. Choosing easily biodegradable toluene and a relatively simple structure as the induced substrate in the early domestication period can effectively reduce the mortality of the microorganisms during the adaptation period and shorten the time needed to adapt to an external carbon source. Ortiz et al (2003) used toluene as the co-substrate for phenanthrene metabolism in soil, and the phenanthrene metabolism rate increased from $39-86 \%$ within $190 \mathrm{~h}$, increasing the enzyme activity of the daughter products. Related studies have also shown that catechol can be used as a carbon source by most of the isolates in the PAHs-degrading flora, and is the typical intermediate metabolite of the PAH degradation pathway (Torres-Farrada et al. 2019). As an intermediate substrate for the domestication of the mixed microbial consortium, it facilitates further degradation of pollutants.

Coking sludge wastewater contains phenols, refractory PAHs, and heterocyclic compounds including nitrogen, oxygen, and sulfur, which provide a natural living environment for the mixed microbial consortium and biosurfactant-producing microorganisms (Zhang et al. 2012). The purpose of this research was to: (1) adopt toluene-catechol-anthracene multi-substrate domestication to screen mixed microbial consortia with synergistic metabolic activity from coking sludge wastewater, and optimize biodegradation conditions of domesticated microbial flora, (2) separate and screen out a biosurfactantproducing strain with the highest biosurfactant-producing ability from the coking sludge; and (3) study the biodegradation pathway of anthracene by the mixed microbial consortium and biosurfactantproducing bacteria. 


\section{Materials And Methods}

\subsection{Strains, chemicals, and mediums}

The activated sludge was taken from the aeration tank of the Weitian Chemical Coking Plant in Xuzhou City, Jiangsu Province, China. The chemicals used in the experiment were analytical grade. Among them, ANT was purchased from Yongkuo Technology Co., Ltd (Shanghai, China), and the rest were purchased from Yien Chemical Reagent Co., Ltd (Shanghai, China).

The Luria-Bertani (LB) medium (in $\mathrm{g} \mathrm{L}^{-1}$ ) contained: beef extract, 3; peptone , 10 ; $\mathrm{NaCl}$, 3; and pH was adjusted to 7. The mineral salt medium (MSM) (in $\mathrm{g} \mathrm{L}^{-1}$ ) comprised: $\mathrm{NaNO}_{3}, 0.5 ; \mathrm{K}_{2} \mathrm{HPO}_{4}, 3 ; \mathrm{NaH}_{2} \mathrm{PO}_{4}, 1$; $\mathrm{MgSO}_{4} .7 \mathrm{H}_{2} \mathrm{O}, 0.5 ;\left(\mathrm{NH}_{4}\right)_{2} \mathrm{SO}_{4}, 0.5 ; \mathrm{CaCl}_{2}, 0.02 ;$ and $\mathrm{pH}$ was adjusted to 7 .

\subsection{Domestication of mixed microbial consortium}

Table 1 shows the cultivation process for mixed microbial consortia to adopt progressive domestication of the toluene-catechol-anthracene multi-substrate within 30 days, and methods to add substrate in the domestication process. During the domestication process, inorganic nutrients (in $\mathrm{g} \mathrm{L}^{-1}$ ) were added that included: $\mathrm{NH}_{4} \mathrm{Cl}, 1.0 ; \mathrm{KH}_{2} \mathrm{PO}_{4}, 1.5 ; \mathrm{K}_{2} \mathrm{HPO}_{4}, 0.5$ and $\mathrm{MgSO}_{4} \cdot 7 \mathrm{H}_{2} \mathrm{O}, 1.0$; along with trace elements consisting of (in mg L-1): $\mathrm{H}_{3} \mathrm{BO}_{3}, 50 ; \mathrm{Kl}, 10 ; \mathrm{CuSO}_{4} \cdot 5 \mathrm{H}_{2} \mathrm{O}, 10 ; \mathrm{MnSO}_{4} \cdot \mathrm{H}_{2} \mathrm{O}, 45 ; \mathrm{NaMoO}_{4}, 20 ; \mathrm{CoCl}_{2}, 50$; $\mathrm{FeCl}_{3}, 12$ and $\mathrm{CaCl}_{2} \cdot 2 \mathrm{H}_{2} \mathrm{O}, 15$.

Table 1

The method for adding substrate in the domestication process

\begin{tabular}{|c|c|c|c|}
\hline \multirow[t]{2}{*}{ Domestication days } & \multicolumn{3}{|c|}{ Substrate ( $\mathrm{g} \mathrm{L}^{-1}$ activated sludge) } \\
\hline & Toluene & Catechol & Anthracene \\
\hline 1 & \multicolumn{3}{|c|}{ Aeration only to consume carbon source and nutrients in activated sludge } \\
\hline 5 & 0.5 & - & - \\
\hline 4 & 0.5 & 0.5 & -- \\
\hline 4 & -- & 0.5 & - \\
\hline 2 & -- & 0.5 & 0.02 \\
\hline 2 & -- & -- & 0.05 \\
\hline 12 & -- & -- & $0.1-0.15^{\mathrm{a}}$ \\
\hline
\end{tabular}

\subsection{High-throughput sequencing to identify bacterial community structure and diversity}


DNA purification test kits were used to extract total genomic DNA from biological samples before and after domestication. The 16S rRNA gene of the V3-V4 region identified from the extracted genomic DNA was amplified using the primers $341 \mathrm{f}$ (5'-CCTAYGGGRBGCASCAG-3') and 806R (5'-

GGACTACNNGGGTATCTAAT-3'). DNA extraction and polymerase chain reaction (PCR) amplification were completed by Majorbio Co., Ltd (Shanghai, China), followed by sequencing of these libraries on the Miseq-PE300 platform.

\subsection{Isolation, screening and identification of biosurfactant- producing bacteria}

A culture bottle containing $90 \mathrm{~mL}$ of LB medium was inoculated with $5 \mathrm{~mL}$ of a sludge-water mixture and placed in a rotary shaker at $30^{\circ} \mathrm{C}(120 \mathrm{rpm}, \mathrm{CRY}-100 \mathrm{~B}) .50 \mathrm{ml}$ of the suspension was centrifuged (FC5515R, Guangzhou), and the supernatant was washed repeatedly with MSM solution after centrifugation. Subsequently, $10 \mathrm{ml}$ of the supernatant was inoculated into flasks containing $90 \mathrm{~mL} \mathrm{MSM}$ supplemented with $1 \%(v / v)$ coal tar, transferred to a fresh MSM every three days, and domesticated repeatedly for ten cycles. $100 \mu \mathrm{l}$ of domesticated bacterial fluid,diluted to different concentration gradients of $10^{-1}, 10^{-2}, 10^{-3}$, and $10^{-4}$, respectively, was coated on the sterilized oil plate supplement with $1 \%(v / v)$ coal tar, $2 \%$ agar and MSM, and was then placed in a biochemical incubator (SPX-250, Shanghai) at $30{ }^{\circ} \mathrm{C}$ to grow for three days. A single-use inoculation ring was used to select colonies with large oleophilic circles in the ultra-clean stand (SW-CJ-1FD, Shanghai) that were placed in LB medium for two days. They were then streaked on the oil plate again to more complete separation and purification. Colonies with large oleophilic circles were preserved and then inoculated into LB medium for four days. The supernatant was then vortexed in a centrifuge $(9,000 \mathrm{rpm}$ for $15 \mathrm{~min})$ to remove the bacterial cells, followed by measurements of the surface tension (Zhang et al. 2016), the oil spreading diameter (Datta et al. 2018), and the emulsification index $\left(E_{24}\right)$ (Deng et al. 2020) were measured. Finally, seven bacterial strains (denoted as strains DM1, DM2, DM3, DM4, DM5, DM6, and DM7) that might produce biosurfactant were obtained. After the above screening, the strain DM3 with the highest biosurfactant production performance was separated and purified again by streaking on the oil plate and stored in the slant culture medium without observing miscellaneous bacteria. At the same time, the growth and degradation effects of DM3 culture $(5 \%, v / v)$ in the presence of $40 \mathrm{mg} \mathrm{L}^{-1}$ ANT were investigated.

\subsubsection{S rDNA gene sequence analysis of biosurfactant- producing bacteria}

The logarithmic phase suspension of the strain DM3 inoculated into LB medium was collected in a $1.5 \mathrm{ml}$ centrifuge tube, then extracted via DNA test kits. The DNA fragment coding was amplified by 16S rRNA universal primers 27F (5'-AGAGTTTGATCCTGGCTCAG-3') and 1492R (5'-GGTTACCTTGTTACGACTT-3'), and then electrophoretically detected under $1 \%$ agarose gel and electrophoresis at $120 \mathrm{~V}$ for $30 \mathrm{~min}$. The amplified 16S rDNA sequence was tested on the $5670 \mathrm{GL}$ sequencer to obtain abi sequence map data. First-generation sequence data were edited and analyzed using Bioedit, and BLAST analysis was 
compared with the Nucleotide Sequence Database (accession ID of MG KT799669.1) to obtain information for establishing the phylogenetic tree by NJ neighbor method using the software PHYLIP 3.69 .

\subsubsection{Extraction and characterization of biosurfactant}

The bacterial culture solution was centrifuged at $8,000 \mathrm{rpm}$ for $10 \mathrm{~min}$ to obtain the cell-free supernatant, which was adjusted to $\mathrm{pH} 2.0$ with $1 \mathrm{~N} \mathrm{HCl}$ and then kept overnight at $4^{\circ} \mathrm{C}$. The supernatant obtained was extracted three times with an equal amount of ethyl acetate, shaken vigorously, and the organic phase was separated in a separatory funnel. The separated organic phases were combined, dried with anhydrous $\mathrm{Na}_{2} \mathrm{SO}_{4}$, and transferred to a round bottom flask connected to a rotary evaporator (RE-52A, Shanghai). The clear solution was concentrated at $40^{\circ} \mathrm{C}$ to evaporate the solvent, leaving behind a relatively pure biosurfactant, which is a viscous, yellow-brown substance. $1 \mathrm{mg}$ of crude biosurfactant was ground evenly with $10 \mathrm{mg}$ potassium bromide to prepare the sample, and tablets were pressed (7,500 kg for $30 \mathrm{~s}$ ) to produce translucent particles for Fourier transform infrared spectroscopy (FT-IR) analysis. FT-IR was performed in transmittance mode of $400-4000 \mathrm{~cm}^{-1}$ with a resolution of $4 \mathrm{~cm}^{-1}$ and an average of 32 scans.

\subsection{Biodegradation assay of ANT under different culture conditions}

After centrifuging the mixed bacterial fluid domesticated and DM3 bacterial fluid in LB medium, the supernatant was washed with MSM solution to obtain $\mathrm{OD}_{600}=1.0$ as inoculum. Different temperatures, $\mathrm{pH}$, and initial concentrations of ANT were selected to explore the optimal conditions for ANT degradation by the mixed microbial consortium. After evaporation of acetone from sterilized $250 \mathrm{~mL}$ Erlenmeyer flasks containing different volumes of stock ANT solution $\left(40 \mathrm{mmol} \mathrm{L}^{-1}\right)$ in acetone, different initial ANT concentrations $\left(10,20,30,40\right.$, and $50 \mathrm{mg} \mathrm{L}^{-1}$ ) were formed. At an initial ANT concentration of $40 \mathrm{mg} \mathrm{L}^{-1}$, $0.75 \mathrm{~mL}$ of mixed, domesticated bacterial fluid $(5 \%, v / v)$ was inoculated into flasks with $150 \mathrm{ml}$ of sterilized MSM. Then, biodegradation assays of ANT were carried out at different culture temperatures $\left(20,25,30,35,40\right.$, and $45^{\circ} \mathrm{C}$ at $\left.\mathrm{pH} 7\right)$ and different $\mathrm{pH}$ values $\left(4,5,6,7,8,9\right.$, and 10 at $\left.30^{\circ} \mathrm{C}\right)$. Different initial concentrations of ANT were tested at the optimal temperature and $\mathrm{pH}$. These flasks were filled with MSM containing 5\% $(v / v)$ mixed bacterial fluid domesticated with 5\% $(v / v)$ DM3 bacterial fluid were investigated for the performance of enhanced biodegradation of ANT $\left(40 \mathrm{mg} \mathrm{L}^{-1}\right)$ at $30{ }^{\circ} \mathrm{C}$ and $\mathrm{pH} 7.5 \%$ $(v / v)$ DM3 bacterial fluid was replaced by an equal volume of MSM in the control group. All the flasks were placed in a shaker (120 rpm).

\subsection{Identification of metabolites}

On day two and day five of ANT degradation, the bacterial fluid was filtered through glass wool and centrifuged. The supernatant was acidified to $\mathrm{pH} 2-3$ with $6 \mathrm{~N} \mathrm{HCl}$, then vortexed with an equal volume of ethyl acetate. After standing, the ethyl acetate layer was removed and extracted again with the same method. The two extracts were combined and dehydrated with anhydrous $\mathrm{Na}_{2} \mathrm{SO}_{4}$. After removing the 
anhydrous $\mathrm{Na}_{2} \mathrm{SO}_{4}$, the combined extract was vacuum distilled in a $40^{\circ} \mathrm{C}$ water bath to near dryness. The volume was made constant with methanol, filtered through a $0.22 \mu \mathrm{m}$ membrane, and added to a $1.5 \mathrm{ml}$ chromatographic sample bottle. The final extract was analyzed by gas chromatography-mass spectrometry (GC-MS; Agilent 7890 A,5975 C) in SIM mode. The injector temperature was programmed from ambient temperature to $360^{\circ} \mathrm{C}$, while the column box temperature was fixed at $350^{\circ} \mathrm{C}$. Nitrogen was used as the carrier gas, and the temperature program was set as follows: $80^{\circ} \mathrm{C}$ for $1 \mathrm{~min}$, then increased to $240^{\circ} \mathrm{C}$ at the speed of $5^{\circ} \mathrm{C} \mathrm{min}^{-1}$, and held for $5 \mathrm{~min}$.

\subsection{Analytical methods}

The residual ANT was analyzed by high-performance liquid chromatography (HPLC; 6890N, Shanghai) (Simarro et al. 2011). $15 \mathrm{ml}$ of culture, added to an equal volume of cyclohexane, was extracted three times to combine with organic phase. The organic phase was concentrated at $40^{\circ} \mathrm{C}$ in a rotary evaporator, with cyclohexane to clean the round bottom flask and diluted to $2 \mathrm{ml}$. The HPLC system was equipped with a photodiode array detector and Nucleosil 100-5 C18 column (length $30 \mathrm{~m}$, inner diameter $0.32 \mathrm{~mm}$, particle size $10 \mu \mathrm{m})$. The injection volume was $1 \mu \mathrm{L}$. Acetonitrile (80\%) was used as the mobile phase,

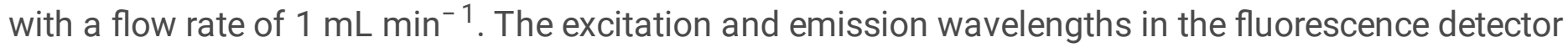
were set to $240 \mathrm{~nm}$ and $420 \mathrm{~nm}$, respectively. The retention time of ANT is $13.5 \pm 0.2$ minutes. The optical density of bacterial fluid was determined using a UV-Vis spectrophotometer (UV1800, Guangdong) at 600 $\mathrm{nm}$.

Data statistics and fitting are carried out using IBM ${ }^{\circledR}$ SPSS ${ }^{\circledR}$ Statistics 24.0 and Origin Pro 9.0 software, respectively. Each data point in the tables and figures represents the mean value of triplicate observations, and the error bar represents the standard deviation.

\section{Results And Discussion}

\subsection{Bacterial community structure}

An in-depth understanding of the community structure in the ANT degradation process is of great significance to further understand the consortium. A total of 29,069 and 51,057 valid sequences were obtained from the samples before and after domestication, respectively (Table 2). Related indexes such as Shannon, Simpson, and Chao1 indicated that diversity and richness of the consortium declined after the long-term domestication of multi-substrate. After progressive domestication, Flavobacteriia became the most abundant class, which increased significantly in proportion from $8.88-56.41 \%$ (Fig. 1a). A study reported that after enhanced biotreatment of groundwater contaminated with total petroleum hydrocarbons, Flavobacteriia became the dominant bacteria, accounting for $41 \%$ of the total population (Poi et al. 2018). Our results highlighted that the relative abundance of dominant bacteria Flavobacteriia increased more significantly after toluene-catechol-anthracene multi-substrate domestication. Flavobacteriia is a typical polycyclic aromatic hydrocarbon degrader that can degrade pyrene, naphthalene, phenanthrene, pyrene, anthracene (Zhao et al. 2017). The metabolic versatility of 
Flavobacteriia played an important role in this community succession under multi-substrate stress. Additionally, Alphaproteobacteria was the second-largest strain, but the difference was not obvious before and after domestication, from 17.92-17.38\% (Fig. 1a). However, the proportion of Bataproteobacteria and Gammaproteobacteria, with relatively large populations before domestication, dropped to $11.23 \%$ and $3.81 \%$, respectively. This agrees with previous research results that showed Alphaproteobacteria more dominant than Bataproteobacteria and Gammaproteobacteria under the PAHinduced bacterial community changes (Zhou et al. 2009). Moreover, Alphaproteobacteria could also utilize PAHs as a carbon source. Zhao et al (2017) detected Alphaproteobacteria as the dominant population in soil contaminated with phenanthrene, whose characteristic phenanthrene-degrading genes were vital in the degradation process of contaminants. The mixed microbial consortium, mainly represented by Flavobacteriia, Alphaproteobacteria, and Bataproteobacteria adapted to the pressure of this multi-substrate selection, which reflected resistance and stability of its community structure. Another study has reported that under different substrates, the structure of the domesticated community is significantly different, and as the domestication time extends, the community structure tends to become stable as the degradation ability increases (Ma et al. 2015).

Table 2

Sequences, richness, and diversity index of the mixed microbial consortium before and after domestication

\begin{tabular}{|lllll|}
\hline Samples & Sequences & Shannon & Simpson & Chao1 \\
\hline before domestication & 29,069 & 4.24 & 0.029 & 455.74 \\
\hline after domestication & 51,057 & 2.42 & 0.278 & 403.55 \\
\hline
\end{tabular}

Changes in the distribution of 33 genera $(>1 \%)$ before and after domestication can be seen in Fig. $1 \mathrm{~b}$. Although species abundance among 23 genera exceeded 1\% before domestication, the differences in microbial abundance and dominant genera were not significant. Six genera of them that accounted for more than 5\% included norank_f_Xanthomonadaceae (9.07\%), norank_o_JG30-KF-CM45 (8.76\%), Thauera (7.29\%), norank_f_Anaerolineaceae (7.09\%), norank_f_Blastocatellaceae_Subgroup_4_ (6.08\%), norank_f_NS9_marine_group (5.40\%). However,the uniformity of the mixed microbial consortium was disturbed after domestication, with the relative abundance of 12 genera greater than $1 \%$. Surprisingly, 10 genera including Myroides, Brevundimonas, Paenalcaligenes, Pseudogracilibacillus, Enterobacter, unclassified_f__Brucellaceae, Enterococcus, Bordetella, Lysinibacillus, Alcaligenes, except for norank_o_JG30-KF-CM45 and Thauera, accounted for less than $1 \%$ before domestication. In particular, two genera, Myroides and Brevundimonas, which grew and reproduced in large quantities after domestication experienced dramatic increases in relative abundance to $55.53 \%$ and $12.28 \%$, respectively, and eventually became dominant genera. The other eight genera are Paenalcaligenes (4.36\%), Pseudogracilibacillus (2.35\%), Enterobacter(1.93\%), unclassified_f_Brucellaceae (1.75\%), Enterococcus (1.66\%), Bordetella (1.66\%), Lysinibacillus (1.29\%), and Alcaligenes (1.14\%), respectively. Smulek et al (2020) reported that the microorganisms Pseudomonas mendocina and Brevundimonas olei isolated 
from soil samples contaminated with creosote could degrade more than $60 \%$ of PAHs. Furthermore, Domingues et al (2020) isolated Brevundimonas which was able to synthesize biosurfactants from ocean and estuary sediments. Interestingly, Myroides has also been widely researched to augment and enhance the biodegradation of hydrocarbon by producing biosurfactants (Chikere et al. 2019).

The above data illustrated that the toluene-catechol-anthracene domestication mode could effectively shift the community structure, and had a significant effect on the selection of high-efficiency dominant degrading bacteria with rich functions. Generally, a method to construct a consortium comprised of mixed microorganisms with equal proportions is straightforward to deplete the compound of interest, but it does not consider the possible inhibitory effect of inoculated microorganisms or intermediates in the metabolic process (Zafra et al. 2017). In our work, microorganisms with better adaptability to pollutants gradually emerged and replaced those with poor adaptability during the process of multi-substrate induced selection. Given that a small amount of fungi exist in the activated sludge of coking wastewater (Joshi et al. 2016), the mixed microbial consortium most likely covers them, which is the focus of future research.

\subsection{Isolation and identification of biosurfactant-producing strains}

Through screening, seven bacterial strains that might produce biosurfactant were finally obtained, with the oil spreading diameter, emulsification index, and surface tension summarized in Table 3. The oil spreading diameter of strain DM1 and DM7 was significantly lower than that of other strains, and the surface tension was $65.7 \mathrm{mN} \mathrm{m}^{-1}$ and $69.1 \mathrm{mN} \mathrm{m}^{-1}$, respectively, an almost negligible decrease; hence, these two strains produced little biosurfactant. The strain DM3 showed the largest oil spreading diameter $\left(73.9 \mathrm{~mm}\right.$ ), the most decreased surface tension of suspension (from $73.4 \mathrm{mN} \mathrm{m}^{-1}$ to $37.6 \mathrm{mN} \mathrm{m}^{-1}$ ), and much better emulsification performance (22.1\%). It was selected as the target biosurfactant producing bacteria with the highest production ability. Moreover, the biological phylogenetic tree constructed by $\mathrm{NJ}$ neighboring method found that strain DM3 had the closest relationship with Pseudomonas_aeruginosa (similarity was close to 100\%) (Fig. S1), and the FT-IR analysis further confirmed that the synthesized biosurfactant had a rhamnolipid nature. The absorption peaks at $1020-1030 \mathrm{~cm}^{-1}, 1560-1580 \mathrm{~cm}^{-1}$, $1740 \mathrm{~cm}^{-1}, 2853 \mathrm{~cm}^{-1}, 3385-3390 \mathrm{~cm}^{-1}$, suggested that the biosurfactant contained bonds -C-O-C-, $\mathrm{COO}-,-\mathrm{C}=\mathrm{O},-\mathrm{C}-\mathrm{H}$, and $-\mathrm{O}-\mathrm{H}$, respectively (Fig. S2). Additionally, it was verified that Pseudomonas_aeruginosa strain DM3 could utilize ANT in this study. Although the strain DM3 was limited to degradation, it could grow stably with ANT $\left(40 \mathrm{mg} \mathrm{L}^{-1}\right)$ as the sole carbon source. The degradation ratio of ANT by the Pseudomonas_aeruginosa DM3 reached $8.9 \%$ and $26.8 \%$ on day 2 and day 6 , respectively, with an increase in the number of bacteria from $\mathrm{OD}_{600}=0.147$ to $\mathrm{OD}_{600}=0.423$ in the reaction (Fig. S3). 
Table 3

Oil spreading diameter, $E_{24}$ and surface tension values of isolated strains

\begin{tabular}{|llll|}
\hline $\begin{array}{l}\text { Strain } \\
\text { number }\end{array}$ & $\begin{array}{l}\text { Oil } \\
\text { spreading } \\
\text { diameter } \\
(\mathrm{mm})\end{array}$ & $\begin{array}{l}\text { Surface tension } \\
\left(\mathrm{mN} \mathrm{m}^{-1}\right)\end{array}$ & $E_{24} / \%$ \\
\hline DM1 & 23.4 & 65.7 & 2.7 \\
\hline DM2 & 57.6 & 43.1 & 20.3 \\
\hline DM3 & 73.9 & 37.6 & 22.1 \\
\hline DM4 & 27.9 & 62.1 & 3.4 \\
\hline DM5 & 70.2 & 38.9 & 22.3 \\
\hline DM6 & 43.7 & 48.3 & 17.4 \\
\hline DM7 & 18.2 & 69.1 & 2.1 \\
\hline
\end{tabular}

\subsection{Microbial consortium biodegradation of ANT under different culture conditions}

After 15 days of cultivation, the density of mixed microbial fluid and ANT degradation ratio were analyzed. When the temperature rose from $20^{\circ} \mathrm{C}$ to $30^{\circ} \mathrm{C}$, the degradation ratio of $A N T$ and $\mathrm{OD}_{600}$ increased, peaking at $30^{\circ} \mathrm{C}$, where $\mathrm{OD}_{600}$ was 0.673 and the degradation ratio reached $80.7 \%(p<0.05)$. As the temperature continued to rise $\left(>30^{\circ} \mathrm{C}\right)$, the degradation ratio of $A N T$ and $\mathrm{OD}_{600}$ both decreased (the lowest at $45^{\circ} \mathrm{C}$ ) (Fig. 2a). With increasing temperature, the diffusion coefficient and solubility of PAHs increased, resulting in enhanced bioavailability and biodegradation, but the temperature could also affect the physiological structure of bacteria, such as enzyme activity.

The mixed microbial consortium had a wide range of $\mathrm{pH}$ values, where at $\mathrm{pH} 4$ and $\mathrm{pH} 10$ the degradation ratio still reached $32.5 \%$ and $34.9 \%$, respectively (Fig. 2 b). However, growth under acidic and alkaline conditions was significantly inhibited compared to the neutral environment $\left(\mathrm{OD}_{600}=0.685\right)$ where the degradation ratio reached $80.5 \%$. In the process of bioremediation, $\mathrm{pH}$ is an important factor affecting the solubility of PAHs and bacterial cell metabolism. Generally, PAH-degrading strains or consortia prefer to grow and degrade PAHs under natural or alkaline pH conditions (Muangchinda et al. 2018). In this experiment, the mixed microbial consortium showed the best performance at $\mathrm{pH} 7\left(\mathrm{OD}_{600}=0.685\right.$; degradation ratio $=80.5 \%)(p<0.05)$.

When ANT was used as the sole carbon source, increased $\mathrm{OD}_{600}$ value indicated that the mixed microbial consortium could utilize ANT to grow (Fig. 2c). The results revealed that the bacterial growth in the low concentration group reached the fixed stage fairly quickly $\left(10 \mathrm{mg} \mathrm{L}^{-1}\right.$ and $20 \mathrm{mg} \mathrm{L}^{-1}$ on day 4 and day 6 , 
respectively), whereas the other concentration group reached this stage on the eighth day. The maximum $\mathrm{OD}_{600}$ of the low concentration group was also less than that of the other concentration group (Fig. 2c).

This may be attributed to the lack of a nutrient supply and the rapid consumption of carbon sources. ANT at a concentration of $40 \mathrm{mg} \mathrm{L}^{-1}$ performed better on the growth of microorganisms. Although the growth ratio was slightly slower in the first six days, which might be owing to the gradual increase in the number of bacteria that competed for carbon sources, the $\mathrm{OD}_{600}$ value at the initial concentration of $40 \mathrm{mg} \mathrm{L}^{-1}$ was significantly higher than that of other concentration from the sixth day $(p<0.05)$. The accumulation of toxic intermediate products during the ANT degradation also caused a reduction in the number of bacteria. As for the initial ANT concentration $50 \mathrm{mg} \mathrm{L}^{-1}$, the $\mathrm{OD}_{600}$ was slightly lower than that of the other concentration groups in the first 4 days. As high PAHs concentration were cytotoxicity, there was a period of biological inhibition that resulted in a final maximum $\mathrm{OD}_{600}$ less than that of $40 \mathrm{mg} \mathrm{L}^{-1}$.

As described in Fig. 2d, when the initial concentration of ANT was 10, 20, 30, 40, and $50 \mathrm{mg} \mathrm{L}^{-1}$, the maximum degradation efficiency on the 16 th day was $56.1 \%, 69.8 \%, 74.1 \%, 85.7 \%$, and $79.6 \%(p<0.05)$, respectively, consistent with the growth-effect curve of $\mathrm{OD}_{600}$ (Fig. 2c). Muangchinda et al (2018) used a dual-substrate enrichment pattern, adding crude oil first and then PAHs to obtain a PAH-degrading bacterial consortium, which biodegraded $68.6 \%$ of ANT $\left(50 \mathrm{mg} \mathrm{L}^{-1}\right)$ after 21 days. This is lower than the degradation rate in our experiment. Active biodegradation mainly occurred during the logarithmic growth phase. After entering the stationary phase, as numbers of bacteria declined due to poor nutrition, the increase in degradation ratio gradually tended to be flat. When the initial concentration was $40 \mathrm{mg} \mathrm{L}^{-1}$, the bacteria had experienced a time interval to adapt to the higher concentration of substrates in the first six days with a degradation ratio below that of other groups, but the removal ratio increased rapidly after the eighth day because of a greater supply of carbon.

\subsection{Enhanced ANT biodegradation combining mixed microbial consortium with strain DM3}

When Pseudomonas_aeruginosa DM3 was added, the degradation ratio and degradation time of ANT had a positive change (Fig. 3a). The ANT degradation ratio in the experimental group (added DM3) was $21.4 \%$, while that in the control group (without DM3) was $16.1 \%$ two days after inoculation. The degradation ratio of ANT in the experimental group increased significantly from the second day. After ten days of inoculation, the ANT degradation ratio in the experimental group and the control group increased slowly, and on the 16th day was $89.2 \%$ and $85.7 \%(P<0.01)$, respectively. Although the system with Pseudomonas_aeruginosa had little effect on the final degradation ratio of ANT, it took 12 days for the control group to reach $83 \%$ and the experimental group reached the same degradation ratio on the sixth day, which significantly shortened the degradation lag phase (Fig. 3a). The model best fitted with the firstorder rate equation has been widely applied to research the biodegradation kinetics of PAHs (Rabodonirina et al. 2019), which was calculated as follows:

$[\mathrm{PAH}]=\left[\mathrm{PAH}_{0}\right] \exp (-k t)$ 
Where [PAH], $\left[\mathrm{PAH}_{0}\right]$ and $k$ are the $\mathrm{PAH}$ concentration at time $t$ (days), the initial amount of $\mathrm{PAH}$, and the first-order rate constant in the reaction, respectively. In this study, the degradation process of ANT by the mixed microbial consortium with or without DM3 is depicted-well in Fig. 3b through the first-order rate equation model, since the obtained $\mathrm{R}^{2}$ value reached 0.984 and 0.959 , respectively. Furthermore, the rate constant $\left(k=0.240 \mathrm{~d}^{-1}\right)$ when DM3 was added was significantly higher than that $\left(k=0.159 \mathrm{~d}^{-1}\right)$ without DM3, increasing nearly 0.5 times within 10 days. The higher the $k$ value, the faster the degradation rate. The corresponding half-life of 2.9 and 4.4 days was calculated according to the equation:

$$
t_{1 / 2}=\ln 2 / k
$$

Where $t_{1 / 2}$ represents the time taken to degrade half of the initial substance. Compared to $t_{1 / 2}=2.9$ days, the half-life $t_{1 / 2}=4.4$ days reduced by nearly $34 \%$, implying less accumulation with DM3 added.

Biodegradation underwent a rapid first phase, in which the bacteria preferentially used easily-available contaminant fragments. A second phase occurred where the degradation might not be governed by microbial activities and slowed down (Fig. 3a). Such a dramatic rise with DM3 co-inoculated in the first stage may result from the following hypothesis. Rhamnolipid produced via strain DM3 could solubilize hydrophobic substrates and increase the hydrophobicity of the cell surface, improving the bioavailability of hydrophobic compounds. Therefore, ANT and the hydrophobic intermediates generated during the metabolic process were rapidly consumed. Other strains, such as Brevundimonas and Myroides in the consortium, may also produce different types of biosurfactants that interact with rhamnolipid. Song et al (2013) explored micelle behaviors of binary mixed biosurfactant systems (sophorolipid/rhamnolipid). The critical micelle concentration (CMC) shifted due to the interaction between molecules. Furthermore, the rhamnolipid synthesized by strain DM3 might be used as a substrate or co-metabolic substrate for certain bacteria in the mixed microbial consortium during the ANT degradation, which promoted the growth of the mixed microbial consortium. The increase in the number of bacteria provided a greater chance of ANT degradation. Ruta and Juozas (2013) revealed that in the presence of rhamnolipid, the activity of related enzymes was greatly increased. Rhamnolipid contributed to activating and reinforcing the activity of mixed microbial consortium enzymes. The crude rhamnolipids, synthetized via strain DM3, of different $\mathrm{CMC}$ were added to the mixed microorganisms, and the highest degradation rate on the sixth day was $71.1 \%$ (Fig. S4). This was significantly lower than in the case when DM3 was added directly (83\%), indicating multiple actions between mixed microorganisms and DM3.

Moreover, mixed cultures with a broader enzymatic mechanism have synergetic metabolism functions through corporation and division of labor by different strains or species, which play different roles (Jia et al. 2019). This designed consortium comprising a mixed microbial consortium and strain DM3 reduced metabolic burden to enable the system to eliminate intermediates rapidly. Previous studies have found that the co-cultivation of exogenous biosurfactant-producing bacteria and indigenous bacterial consortium can effectively improve hydrocarbons degradation (Tao et al. 2017). In this experiment, the indigenous biosurfactant-producing Pseudomonas_aeruginosa DM3 coordinated well with the mixed microbial consortium. 


\subsection{Intermediates analysis in the ANT degradation process}

For the degradation of PAHs, it is important to recognize the complete metabolic pathways by the bacterial consortium with DM3 to avoid the toxicity accumulation of metabolites. To our knowledge, both dioxygenases and monooxygenases can catalyze the initial attack on PAHs,and previous researches have reported two major types of metabolic pathways about ANT degradation (Cui et al. 2014; Moody et al. 2001). One is forming 1,2-dihydroxy-anthracene by deoxygenating the position of C-1 and C-2 rings, followed by generation of 4-(2-hydroxynaphth-3-yl)-2-oxobut-3-enoic acid via the meta-cleavage pathway (Zeinali et al. 2008). However, 4-(2-hydroxynaphth-3-yl)-2-oxobut-3-enoic acid is unstable and converts to 6,7-benzocoumarin, or it can further form 3-hydroxy-2-naphthoic acid (Dean-Ross et al. 2001). Subsequent metabolism occurs through a pathway similar to the biodegradation of naphthalene to produce salicylate or phthalic acid (Zeinali et al. 2008). Another pathway involves the formation 9,10anthraquinone by deoxygenating the positions of C-9 and C-10, followed by further metabolism to phthalic acid via extracellular enzymes (Ahmed et al. 2012). The intermediates of the degradation process of ANT changed over time, forming two metabolite fractions on day two (Fig. 4a) and three metabolite fractions on day five (Fig. 4b) designated P1, P2, P3, and P4, respectively. Having a retention time of $12.531 \mathrm{~min}$, with a molecular ion $\left(\mathrm{M}^{+}\right)$at $\mathrm{m} / \mathrm{z} 144$ and fragment ions at $\mathrm{m} / \mathrm{z} 115,74$, and $63, \mathrm{P} 1$ was identified as 1-naphthalenol (Fig. 4c). Numerous studies in the past have reported that 1naphthalenol is the main metabolite during the degradation of naphthalene (Bubinas et al. 2008). This metabolic pathway of ANT is consistent with the first metabolic pathway mentioned above. Having a retention time of $15.833 \mathrm{~min}$, with a molecular ion $\left(\mathrm{M}^{+}\right)$at $\mathrm{m} / \mathrm{z} 178, \mathrm{P} 2$ was regards as ANT. With retention times of 15.230 and $17.234, P 3$ and $P 4$ with a molecular ion $\left(M^{+}\right)$at $\mathrm{m} / \mathrm{z} 178$ could be phthalic acid derivatives-1,2-benzene dicarboxylic acid, mono (2-ethylhexyl) ester and dibutyl phthalate by reference to GC-MS library. In the present study, some intermediates might be undetected at a certain moment due to low concentration or rapid utilization by the bacterial community after production; hence, additional metabolic pathways related to ANT were likely to be undiscovered. Although 9,10anthraquinone is generally considered to be an end product, it cannot be ruled out that 9,10anthraquinone is converted to phthalic acid in this work. Besides, related studies have reported that microorganisms with two metabolism pathways of ANT include Rhodococcus (Cui et al. 2014), Mycobacterium (Dean-Ross et al. 2001), Martelella (Moody et al. 2001), etc. The mixed microbial consortium with abundant strains has a wide range of enzymatic activities. Two possible metabolic pathways of ANT were hereby proposed (Fig. 5).

\section{Conclusions}

This study presented the effectiveness of multi-substrate domestication to construct a mixed flora. This method could adjust the colony distribution and exerted a significant effect on the screen of dominant degrading bacteria, especially Flavobacteriia. When the temperature was $30^{\circ} \mathrm{C}, \mathrm{pH}$ 7, and the initial ANT concentration $40 \mathrm{mg} \mathrm{L}^{-1}$, the degradation ratio (85.7\%) reached a maximum of 16 days after inoculation via the mixed microbial consortium. Furthermore, the research results corroborated an obvious promotion 
effect of the co-culture with an indigenous biosurfactant-producing strain for ANT degradation, inferring two possible simultaneous metabolic pathways. The degradation ratio of ANT (40 mg L ${ }^{-1}$ ) achieved $89.2 \%$ by the consortium with a Pseudomonas_aeruginosa DM3, and the degradation lag phase was shortened. When the strain DM3 and the mixed microbial consortium were co-inoculated, the rate constant $k$ increased by nearly 0.5 times within 10 days, which is promising for application in bioremediation of PAH contaminants.

\section{Declarations}

Ethics approval and consent to participate: Not applicable.

Consent for publication: Not applicable.

Data availability: The datasets used and/or analyzed during the current study are available from the corresponding author on reasonable request.

Competing interests: The authors declare that they have no competing interests

Funding: This work was supported by the National Natural Science Foundation of China (grant number 51778612 and 51974314).

Authors' contributions: $\mathrm{LW}$ and $\mathrm{WL}$ conceived the research. $\mathrm{YL}$ and $\mathrm{DL}$ contributed new reagents or analytical tools. QW conducted experiments. WL wrote the manuscript. LW and ZM guided and reviewed the manuscript. All authors read and approved the manuscript.

\section{References}

1. Ahmed AT, Othman MA, Sarwade VD et al (2012) Degradation of anthracene by alkaliphilic bacteria bacillus badius. Environment and Pollution 1:97. https://doi.10.5539/ep.v1n2p97

2. Behera BK, Das A, Sarkar DJ et al (2018) Polycyclic Aromatic Hydrocarbons (PAHs) in inland aquatic ecosystems: Perils and remedies through biosensors and bioremediation. Environ Pollut 241:212233. https://doi.10.1016/j.envpol.2018.05.016

3. Bubinas A, Giedraityte $G$, Kalediene $L$ et al (2008) Degradation of naphthalene by thermophilic bacteria via a pathway, through protocatechuic acid. Central European Journal of Biology 3:61-68. https://doi.10.2478/s11535-007-0042-x

4. Cazals F, Huguenot D, Crampon M et al (2020) Production of biosurfactant using the endemic bacterial community of a PAHs contaminated soil, and its potential use for PAHs remobilization. Sci Total Environ 709:12. https://doi.10.1016/j.scitotenv.2019.136143

5. Chikere CB, Tekere M, Adeleke R (2019) Enhanced microbial hydrocarbon biodegradation as stimulated during field-scale landfarming of crude oil-impacted soil. Sustainable Chemistry and Pharmacy 14:10177. https://doi.10.1016/j.scp.2019.100177 
6. Cui C, Ma L, Shi J et al (2014) Metabolic pathway for degradation of anthracene by halophilic Martelella sp AD-3. Int Biodeterior Biodegrad 89:67-73. https://doi.10.1016/j.ibiod.2014.01.012

7. Datta P, Tiwari P, Pandey LM (2018) Isolation and characterization of biosurfactant producing and oil degrading Bacillus subtilis MG495086 from formation water of Assam oil reservoir and its suitability for enhanced oil recovery. Bioresour Technol 270:439-448. https://doi.10.1016/j.biortech.2018.09.047

8. Dean-Ross D, Moody JD, Freeman JP et al (2001) Metabolism of anthracene by a Rhodococcus species. FEMS Microbiol Lett 204:205-211. https://doi.10.1111/j.1574-6968.2001.tb10886.x

9. Dean SM, Jin Y, Cha DK et al (2001) Phenanthrene degradation in soils co-inoculated with phenanthrene-degrading and biosurfactant-producing bacteria. J Environ Qual 30:1126-1133. https://doi.10.2134/jeq2001.3041126x

10. Deng Z, Jiang Y, Chen K et al (2020) One biosurfactant-producing bacteria achromobacter $s p$. A-8 and its potential use in microbial enhanced oil recovery and bioremediation. Frontiers in Microbiology 11:247. https://doi.10.3389/fmicb.2020.00247

11. Domingues PM, Oliveira V, Serafim LS et al (2020) Biosurfactant production in Sub-Oxic conditions detected in hydrocarbon-degrading isolates from marine and estuarine sediments. International Journal of Environmental Research and Public Health 17:1746. https://doi.10.3390/ijerph17051746

12. Elliot R, Singhal N, Swift S (2011) Surfactants and bacterial bioremediation of polycyclic aromatic hydrocarbon contaminated soil-unlocking the targets. Critical Reviews in Environmental Science and Technology 41:78-124. https://doi.10.1080/00102200802641798

13. Gaur N, Narasimhulu K, PydiSetty Y (2018) Recent advances in the bio-remediation of persistent organic pollutants and its effect on environment. Journal of Cleaner Production 198:1602-1631. https://doi.10.1016/j.jclepro.2018.07.076

14. Hadibarata T, Zubir MMFA, Rubiyatno Chuang TZ et al (2013) Microbial transformation and sorption of anthracene in liquid culture. Bioprocess Biosyst Eng 36:1229-1233. https://doi.10.1007/s00449012-0850-x

15. Jia X, He Y, Jiang D et al (2019) Construction and analysis of an engineered Escherichia coliPseudomonas aeruginosa co-culture consortium for phenanthrene bioremoval. Biochem Eng J 148:214-223. https://doi.10.1016/j.bej.2019.05.010

16. Joshi DR, Zhang Y, Tian Z et al (2016) Performance and microbial community composition in a longterm sequential anaerobic-aerobic bioreactor operation treating coking wastewater. Appl. Microbiol Biotechnol 100:8191-8202. https://doi.10.1007/s00253-016-7591-8

17. Lee DW, Lee H, Kwon B-O et al (2018) Biosurfactant-assisted bioremediation of crude oil by indigenous bacteria isolated from Taean beach sediment. Environ Pollut 241:254-264. https://doi.10.1016/j.envpol.2018.05.070

18. Ma J, Qu JF, Yan AH et al (2015) Development of bacterial consortia and biodegradation ability under different PAH stresses. Adv Mat Res 176:1073-1076. https://doi.org/10.4028/www.scientific.net/AMR.1073-1076.176 
19. Mnif I, Sahnoun R, Ellouz-Chaabouni S et al (2017) Application of bacterial biosurfactants for enhanced removal and biodegradation of diesel oil in soil using a newly isolated consortium. Process Safety and Environmental Protection 109:72-81. https://doi.10.1016/j.psep.2017.02.002

20. Moody JD, Freeman JP, Doerge DR et al (2001) Degradation of phenanthrene and anthracene by cell suspensions of Mycobacterium sp. strain PYR-1. Applied and Environmental Microbiology 67:14761483. https://doi.10.1128/aem.67.4.1476-1483.2001

21. Muangchinda C, Rungsihiranrut A, Prombutara $P$ et al (2018) 16 S metagenomic analysis reveals adaptability of a mixed-PAH-degrading consortium isolated from crude oil-contaminated seawater to changing environmental conditions. J Hazard Mater 357:119-127. https://doi.10.1016/j.jhazmat.2018.05.062

22. Ortiz I, Auria R, Sigoillot JC et al (2003) Enhancing phenanthrene biomineralization in a polluted soil using gaseous toluene as a cosubstrate. Environmental Science \& Technology 37:805-810. https://doi.10.1021/es0260061

23. Patowary R, Patowary K, Kalita MC et al (2018) Application of biosurfactant for enhancement of bioremediation process of crude oil contaminated soil. Int Biodeterior Biodegrad 129:50-60. https://doi.10.1016/j.ibiod.2018.01.004

24. Poi G, Shahsavari E, Aburto-Medina A et al (2018) Large scale treatment of total petroleumhydrocarbon contaminated groundwater using bioaugmentation. J Environ Manage 214:157-163. https://doi.10.1016/j.jenvman.2018.02.079

25. Prasanna D, Mohan SV, Reddy BP et al (2008) Bioremediation of anthracene contaminated soil in bio-slurry phase reactor operated in periodic discontinuous batch mode. J Hazard Mater 153:244251. https://doi.10.1016/j.jhazmat.2007.08.063

26. Rabodonirina S, Rasolomampianina R, Krier F et al (2019) Degradation of fluorene and phenanthrene in PAHs-contaminated soil using Pseudomonas and Bacillus strains isolated from oil spill sites. J Environ Manage 232:1-7. https://doi.10.1016/j.jenvman.2018.11.005

27. Ruta I-G, Juozas K (2013) Effects of rhamnolipid biosurfactant JBR425 and synthetic surfactant Surfynol465 on the peroxidase-catalyzed oxidation of 2-naphthol. Journal of Environmental Sciences 25:1431-1440. https://doi.10.1016/s1001-0742(12)60177-6

28. Simarro R, Gonzalez N, Bautista LF et al (2011) Optimisation of key abiotic factors of PAH (naphthalene, phenanthrene and anthracene) biodegradation process by a bacterial consortium. Water Air and Soil Pollution 217: 365-374. https://doi.10.1007/s11270-010-0593-8

29. Smulek W, Sydow M, Zabielska-Matejuk J et al (2020) Bacteria involved in biodegradation of creosote PAH - A case study of long-term contaminated industrial area. Ecotoxicology and Environmental Safety 187:109843. https://doi.10.1016/j.ecoenv.2019.109843

30. Song DD, Li YM, Liang SK et al (2013) Micelle behaviors of sophorolipid/rhamnolipid binary mixed biosurfactant systems. Colloid Surf A-Physicochem Eng Asp 436:201206. https://doi.10.1016/j.colsurfa.2013.06.011 
31. Sun R, Jin J, Sun G et al (2010) Screening and degrading characteristics and community structure of a high molecular weight polycyclic aromatic hydrocarbon-degrading bacterial consortium from contaminated soil. Journal of Environmental Sciences 22:1576-1585. https://doi.10.1016/s10010742(09)60292-8

32. Tao K, Liu X, Chen X et al (2017) Biodegradation of crude oil by a defined co-culture of indigenous bacterial consortium and exogenous Bacillus subtilis. Bioresour Technol 224:327-332. https://doi.10.1016/j.biortech.2016.10.073

33. Tian W, Yao J, Liu R et al (2016) Effect of natural and synthetic surfactants on crude oil biodegradation by indigenous strains. Ecotoxicology and Environmental Safety 129:171-179. https://doi.10.1016/j.ecoenv.2016.03.027

34. Torres-Farrada G, Manzano-Leon AM, Rineau F et al (2019) Biodegradation of polycyclic aromatic hydrocarbons by native Ganoderma sp. strains: identification of metabolites and proposed degradation pathways. Appl Microbiol Biotechnol 103:7203-7215. https://doi.10.1007/s00253-01909968-9

35. Wanapaisan P, Laothamteep N, Vejarano F et al (2018) Synergistic degradation of pyrene by five culturable bacteria in a mangrove sediment-derived bacterial consortium. J Hazard Mater 342:561570. https://doi.10.1016/j.jhazmat.2017.08.062

36. Xu M, Fu X, Gao Y et al (2020) Characterization of a biosurfactant-producing bacteria isolated from marine environment: Surface activity, chemical characterization and biodegradation. Journal of Environmental Chemical Engineering 8:104277. https://doi.10.1016/j.jece.2020.104277

37. Zafra G, Absalon AE, Angel Anducho-Reyes M et al (2017) Construction of PAH-degrading mixed microbial consortia by induced selection in soil. Chemosphere 172:120126. https://doi.10.1016/j.chemosphere.2016.12.038

38. Zeinali M, Vossoughi M, Ardestani SK (2008) Degradation of phenanthrene and anthracene by Nocardia otitidiscaviarum strain TSH1, a moderately thermophilic bacterium. J Appl Microbiol 105:398-406. https://doi.10.1111/j.1365-2672.2008.03753.x

39. Zhang JH, Xue QH, Gao H et al (2016) Production of lipopeptide biosurfactants by Bacillus atrophaeus 5-2a and their potential use in microbial enhanced oil recovery. Microb Cell Fact 15:11. https://doi.10.1186/s12934-016-0574-8

40. Zhang WH, Wei CH, Chai XS et al (2012) The behaviors and fate of polycyclic aromatic hydrocarbons (PAHs) in a coking wastewater treatment plant. Chemosphere 88:174-182. https://doi.10.1016/j.chemosphere.2012.02.076

41. Zhao H, Zhang Y, Xiao X et al (2017) Different phenanthrene-degrading bacteria cultured by in situ soil substrate membrane system and traditional cultivation. Int Biodeterior Biodegrad 117:269-277. https://doi.10.1016/j.ibiod.2016.12.016

42. Zhou HH, Huang XM, Liang YP et al (2020) Enhanced bioremediation of hydraulic fracturing flowback and produced water using an indigenous biosurfactant-producing bacteria Acinetobacter sp. Y2. Chem Eng J 397:10. https://doi.10.1016/j.ibiod.2016.12.016 
43. Zhou HW, Wong AHY, Yu RMK et al (2009) Polycyclic aromatic hydrocarbon-induced structural shift of bacterial communities in mangrove sediment. Microb Ecol 58:153-160.

https://doi.10.1007/s00248-008-9456-x

\section{Figures}
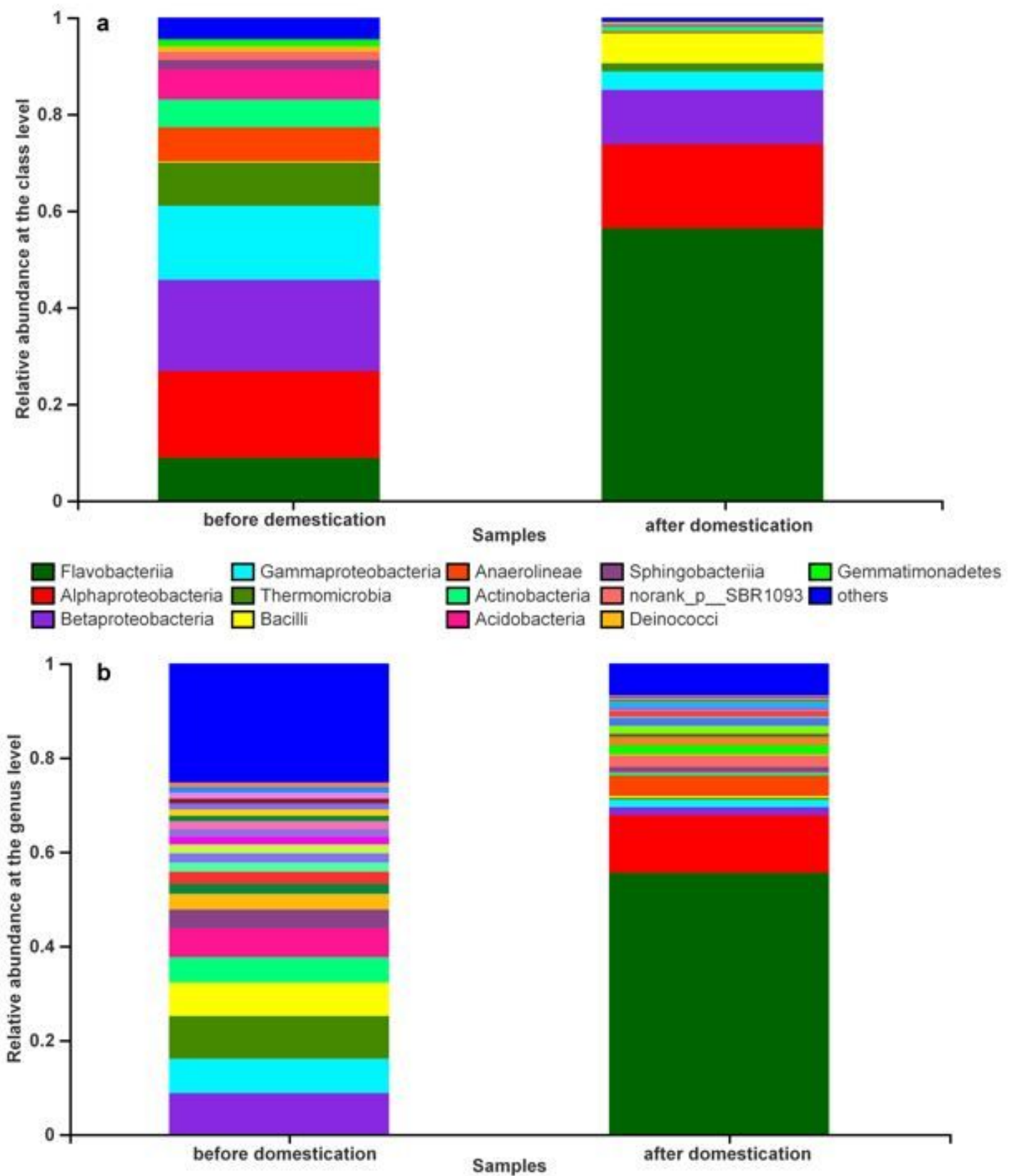

\begin{tabular}{|c|c|c|c|}
\hline Myroides & Limnobacter & $\square$ Pseudomonas & Diaphorobacter \\
\hline Brevundimonas & $\square$ Pseudogracilibacillus & Lysinibacillus & unclassified_f__Phyllobacteriaceae \\
\hline Inorank_o_JJG30-KF-CM45 & $\square$ Woodsholea & Thiobacillus & norank_f__Propionibacteriaceae \\
\hline Thauera & Enterobacter & $\square$ norank_o__1013-28-CG33 & norank_f_KCM-B-15 \\
\hline Inorank_f__ Xanthomonadaceae & unclassified_f__Brucellaceae & Luteococcus & Rivibacter \\
\hline Inorank_f__Anaerolineaceae & Hyphomicrobium & Alcaligenes & unclassified_o_Rhizobiales \\
\hline Paenalcaligenes & Moheibacter & $\square$ norank_P__SBR1093 & others \\
\hline Inorank_f_NS9_marine_group & $\square$ Enterococcus & $\square$ Elioraea & \\
\hline Inorank_f__Blastocatellaceae__Subgroup_4_ & $\square$ Bordetella & Truepera & \\
\hline
\end{tabular}


Distribution analysis of the mixed microbial consortium at the class (a) and genus (b) level before and after domestication.
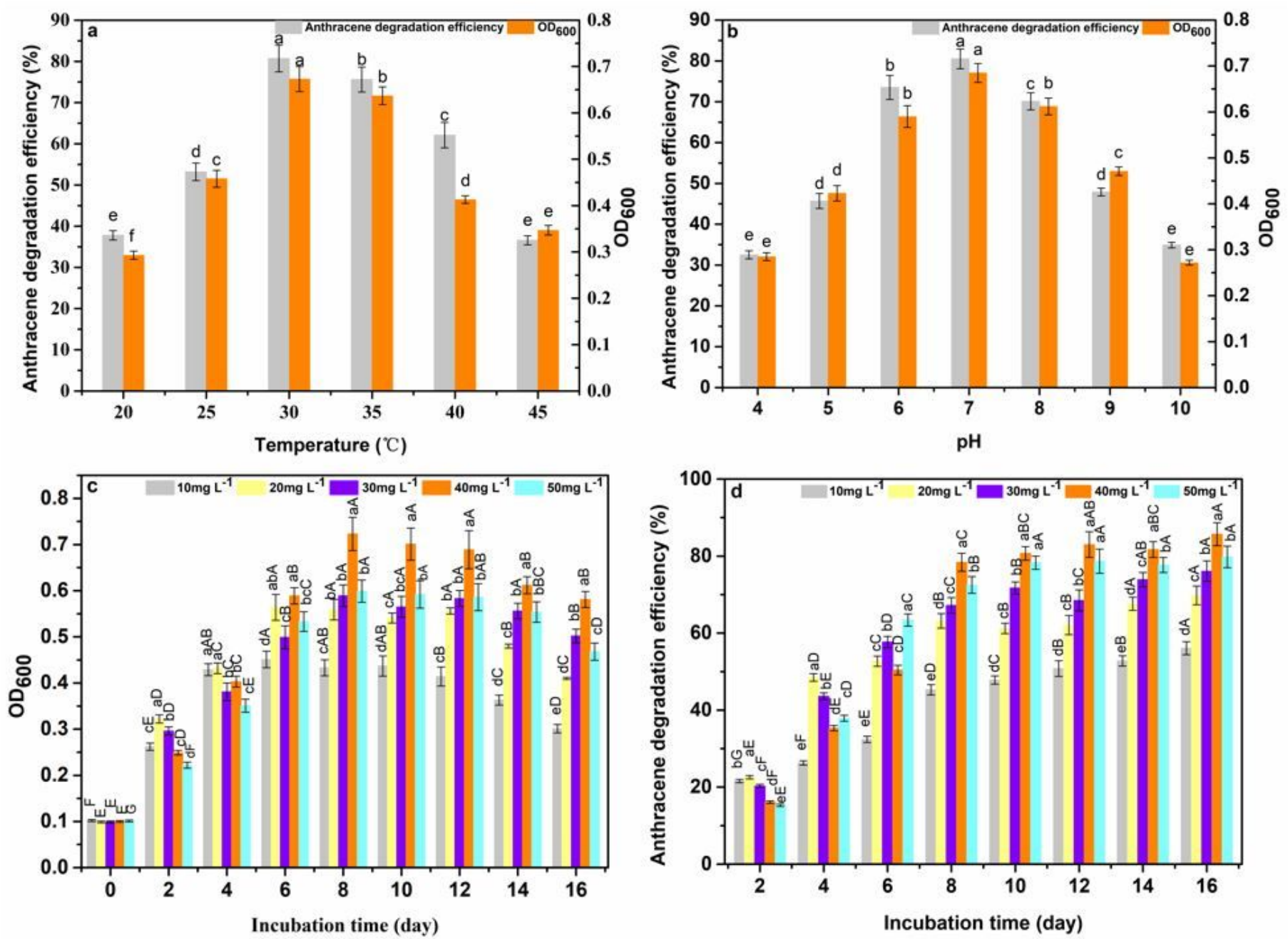

Figure 2

Biodegradation of ANT by the microbial consortium at different temperatures (a) and pH (b); bacterial density of the microbial consortium (c) and degradation efficiency under different initial ANT concentrations (d). Symbols are expressed as the mean values of triplicate data points, with error bars representing standard deviations. Different lowercase letters indicate statistically significant differences at different temperatures (a) and pH values (b). Different lowercase letters indicate significant differences between different concentrations of ANT at each time point, and capital letters indicate significant differences in the same ANT concentration at different time point (c) (d), as determined by Duncan's multiple range test $(p<0.05)$. 

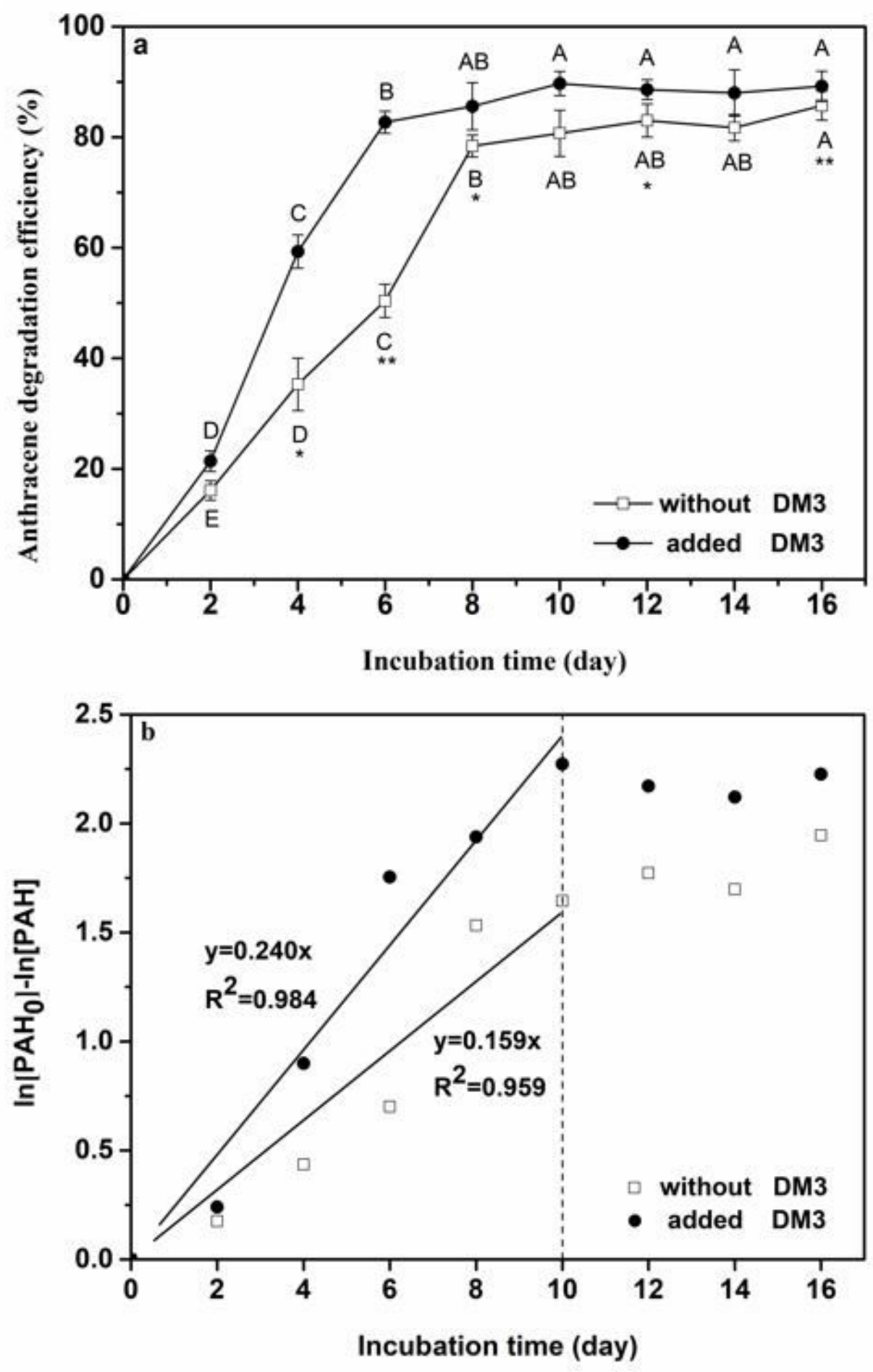

Figure 3

The efficiency (a) and first-order model (b) of ANT degradation by the microbial consortium with or without DM3. Symbols are shown as the average values of triplicate observations, and error bars represent standard deviations. Different capital letters indicate significant differences in the same treatment group at different time points through Duncan's multiple range test $(p<0.05)$; $(p<0.05)$ and 
** $(p<0.01)$ indicate significant differences between the different treated groups at each time point according to t-test.v
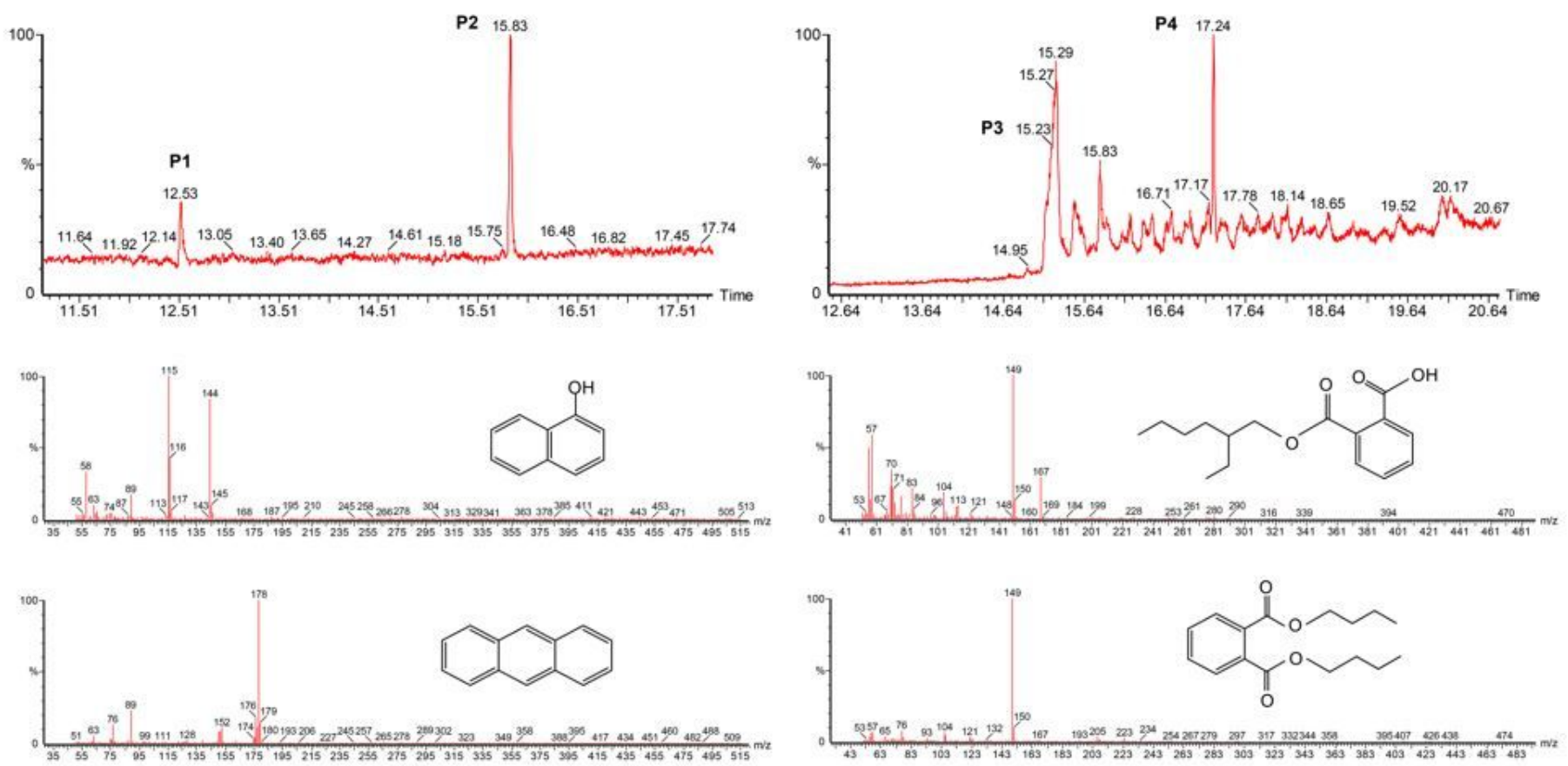

\section{Figure 4}

Chromatograms of intermediates in the degradation process of ANT by the mixed microbial consortium with DM3 on day two(a) and day five(b); mass spectrum of each intermediate during ANT degradation (c). 


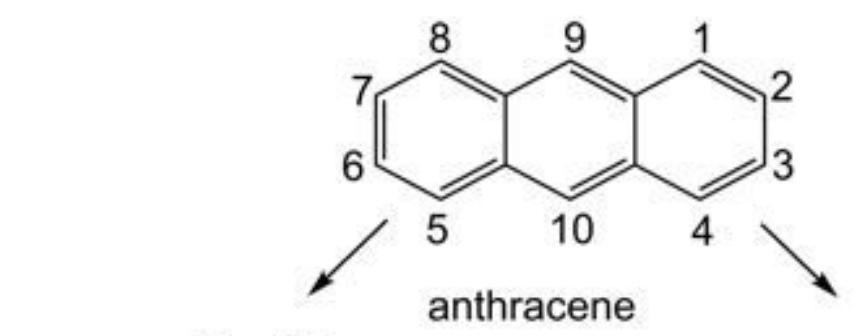<smiles>OC1c2ccccc2C(O)c2ccccc21</smiles>

anthracene-9,10-dihydrodiol<smiles>CCOc1c2ccccc2c(C)c2ccccc12</smiles>

$\mathrm{OH}$

9,10-dihydroxyanthracene<smiles>C=C(O)c1ccccc1C(=O)O</smiles>

$\mathrm{O}$

phthalic acid<smiles>O[C@H]1C=Cc2cc3ccccc3cc2[C@H]1O</smiles>

anthracene-1,2-dihydrodiol<smiles>Oc1ccc2cc3ccccc3cc2c1O</smiles>

1,2-dihydroxyanthracene<smiles>Oc1cccc2ccccc12</smiles>

1-naphthol

Figure 5

Proposed pathway of anthracene metabolism. The substances in brackets were not detected, and the dotted arrows indicated the possible pathway.

\section{Supplementary Files}

This is a list of supplementary files associated with this preprint. Click to download.

- GraphicalAbstract.jpg 
- Supplementarymaterial.docx

Page 23/23 